\title{
CAUSATIVIZAÇÃO DE PREDICADORES ESTÁTICOS E PROCESSUAIS NO PORTUGUÊS BRASILEIRO*
}

\author{
SANIR DA CONCEIÇÃO \\ APÓSTOLOT.NICOLACÓPULOS \\ (UFSC)
}

\begin{abstract}
This paper deals with state and process verbs/predicators in utterances of journalistic texts from a semantic-pragmatic perspective. It claims that when "intention" is added to these predicators, they are causativized, thus encompassing a new semantic (thematic) role, namely the Agent.
\end{abstract}

\section{INTRODUÇÃO}

Este trabalho apresenta uma análise de vinte verbos/predicadores (dez estáticos e dez processuais) que podem ser causativizados em enunciados ${ }^{1}$ de textos jornalísticos. Dizemos que predicadores estáticos e processuais são causativizados quando, no enunciado, ao captar a intenção do sujeito-enunciador, o verbo estático ou processual acrescido do fator intenção passa a atribuir um outro caso ${ }^{2}$, próprio dos verbos de ação, o agentivo.

Os verbos/predicadores analisados são:

Tabela 1 - Verbos/predicadores analisados por este estudo

\begin{tabular}{|c|c|c|c|}
\hline \multicolumn{2}{|c|}{ ESTADO } & \multicolumn{2}{c|}{ PROCESSO } \\
\hline Amar & Pertencer & Acordar & Durar \\
\hline Conhecer & Saber & Aprender & Esquecer \\
\hline Entender & Ser & Cair & Ganhar \\
\hline Estar & Ter & Crescer & Morrer \\
\hline Ignorar & Ver & Dormir & Vencer \\
\hline
\end{tabular}

Levanta-se, como hipótese, que tanto os verbos considerados estáticos quanto os processuais podem ser causativizados, apresentando-se assim como agentivos.

\footnotetext{
* Agradecemos à Profa. Izabel Seara e à Profa. Maria da Graça de Oliveira pelas leituras e sugestões que auxiliaram na execução do trabalho. Qualquer erro, porém, é de nossa responsabilidade.

${ }^{1}$ Por enunciado entende-se "frase, parte de um discurso ou discurso (oral ou escrito) em associação com o contexto em que é enunciado." Cf. Houaiss (2001:1171).

${ }^{2}$ Casos são relações semânticas de nomes que estão em relação de associação com o verbo.
} 
CONCEIÇÃO \& NICOLACÓPULOS - Causativização de predicadores estáticos...

O corpus é composto por 31.692 enunciados jornalísticos que se constituem em exemplários da língua em uso, recolhidos da Folha de São Paulo, no período de 1 a 31 de dezembro de 1997. Teve-se como campo de enunciação todas as seções do jornal (esporte, política, lazer, polícia etc).

A coleta dos dados foi feita através do software desenvolvido pelo Laboratório de Instrumentação Eletrônica: Circuitos e Processamentos de Sinais (LINSE), da Universidade Federal de Santa Catarina. Esse software é um sub-produto dos projetos desenvolvidos pelo referido Laboratório para reconhecimento de fala e conversão texto-fala.

Para se atingir o objetivo do trabalho, fez-se uma revisão da literatura considerando as estratégias apresentadas por diferentes autores, como Cook $(1979,1989)$ e Chafe (1970) para a detecção da classe do verbo: estado, processo ou ação.

Este estudo está embasado no modelo pragmático-semântico desenvolvido por Nicolacópulos (1992), Nicolacópulos et al. (1997), Oliveira (1995), Oliveira (1999) que tem, como ponto de partida, os modelos semânticos de Fillmore (1968, 1977), Chafe (1970), Anderson (1971) e Cook (1979, 1989).

O trabalho está assim organizado: na primeira seção, apresenta-se o aparato teórico, configurando um espaço teórico-metodológico que abriga as dimensões semânticopragmáticas, a fim de possibilitar a interpretação e análise do fenômeno da causativização, que encerra o fator intenção. Na segunda, observam-se as diferentes formas de análise do agentivo, considerando Cruse (1973) que apresenta o agentivo com traços semânticos específicos (volitivo, efetivo, iniciador e agentivo). O enfoque nesse trabalho será sobre o traço volitivo (= intenção). Na terceira seção, mostra-se como se fez a coleta de dados. $\mathrm{Na}$ quarta seção, apresentam-se a análise e os resultados sobre dos predicadores causativizados no português brasileiro (PB).

\section{PERSPECTIVASTEÓRICAS}

\subsection{A Teoria de Casos}

As teorias de Fillmore (1968), Chafe (1970), Anderson (1971) e Cook (1979, 1989) propõem que a estrutura semântica de uma oração se constitui de um verbo e de nomes/ casos que integram a valência semântica desse verbo. Fillmore (1968), por exemplo, apresenta seis tipos de caso: agentivo, instrumental, dativo, factivo, locativo e objetivo. Cook (1979, 1989) apresenta os casos: agentivo, experienciador, benefactivo, objetivo e locativo. Há também os casos modais, mas esses não entram na classificação de verbos, portanto não são definidos dentro do sistema.

Quanto aos tipos de verbos, Fillmore (1968:306) afirma que existem verbos de estado e de não-estado relacionados a quatro campos semânticos: básico, instrumental, dativo e locativo. Cook (1989:14) esquematiza, no Quadro 1, os tipos de verbos possíveis, de acordo com o modelo de Fillmore (1968): 
Quadro 1 - Esquema casual de Fillmore (1968)

\begin{tabular}{|c|c|c|c|c|}
\hline Tipos de verbos & Básico & Instrumental & Dativo & Locativo \\
\hline Estado & $\begin{array}{c}\mathrm{O} \\
\text { quebrar, v.i. }\end{array}$ & $\begin{array}{c}\mathrm{I}, \mathrm{O} \\
\text { quebrar, v. t. }\end{array}$ & $\begin{array}{c}\mathrm{D}, \mathrm{O} \\
\text { gostar }\end{array}$ & $\begin{array}{c}\mathrm{O}, \mathrm{L} \\
\text { estar em }\end{array}$ \\
\hline Ação & $\begin{array}{c}\mathrm{A}, \mathrm{O} \\
\text { quebrar, v. t. }\end{array}$ & $\begin{array}{c}\mathrm{A}, \mathrm{I}, \mathrm{O} \\
\text { quebrar, v. t. }\end{array}$ & $\begin{array}{c}\mathrm{A}, \mathrm{D}, \mathrm{O} \\
\text { mostrar }\end{array}$ & $\begin{array}{c}\mathrm{A}, \mathrm{O}, \mathrm{L} \\
\text { colocar }\end{array}$ \\
\hline
\end{tabular}

Os verbos podem ocorrer em mais de um campo semântico e, conforme o campo, ter esquemas casuais ${ }^{3}$ diferentes.

Em seu modelo, Chafe (1970) introduz a noção de "processo" para a classificação de verbos. O autor faz a divisão dos verbos em estados, processos, ações e ações-processos ${ }^{4}$. Já Cook (1989) classifica os verbos em estados, processos e ações. No entanto, pode-se dizer que, em termos gerais, os verbos classificam-se em estado e não-estado. Um verbo de estado é estático e pode ser melhor definido como um verbo de não-evento. Um verbo de não-estado (evento) pode ser classificado como processo ou ação. $\mathrm{O}$ verbo processual é não-agentivo, enquanto o verbo de ação é agentivo. Veja-se a Figura 1:

Figura 1 - Esquema de tipos de verbos

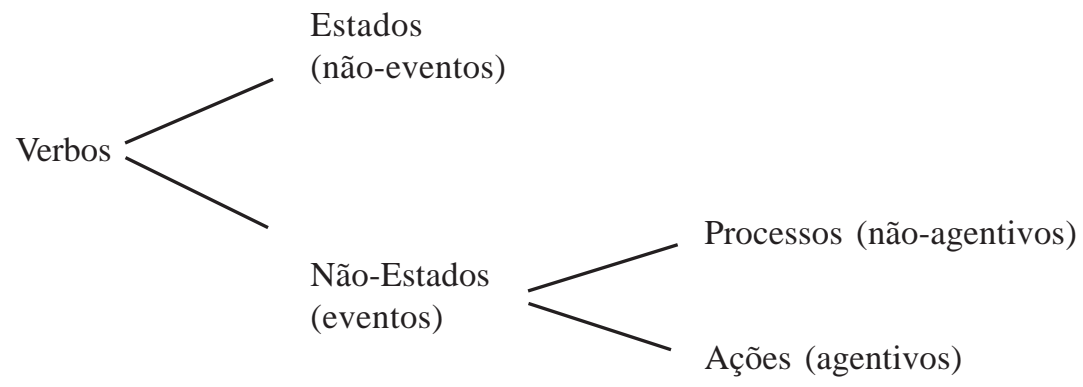

Portanto, os verbos podem ser classificados como estados e não-estados (eventos), sendo este último subdividido em processos e ações.

Cook (1979) utiliza, seguindo Lakoff (1966), Fillmore (1968) e Anderson (1971), o teste [imperativo, progressivo] para identificar estados, processos e ações. O teste [-imperativo, -progressivo] indica os verbos de estado. Observem-se os exemplos:

(1) a. Maria é bonita.

b. ? Seja bonita, Maria. ${ }^{5}$

c. ? Maria está sendo bonita.

${ }^{3}$ Em teoria de casos, os esquemas casuais representam a estrutura semântica da proposição.

${ }^{4}$ Assim, como em Cook (1979, 1989), os verbos classificados como ação-processo em Chafe (1970) serão considerados neste trabalho como de ação.

${ }^{5}$ A interrogação, seguindo Cruse (1973), indica anormalidade da oração. 
CONCEIÇÃO \& NICOLACÓPULOS - Causativização de predicadores estáticos...

O teste não permite que se tenham orações imperativas, como (1b), nem orações progressivas como (1c). Portanto, (1a) é estado.

Os verbos processuais admitem o progressivo, mas não o imperativo, como em:

(2) a. João morreu.

b. ? Morra, João. ${ }^{6}$

c. João está morrendo.

Para (2a), é possível ter uma oração progressiva, como (2c), mas não o imperativo, como (2b). Este teste então indica que se tem (2a) como processo.

$\mathrm{O}$ teste que permite tanto o imperativo como o progressivo identifica o verbo de ação:

(3) a. João vendeu a casa.

b. Venda a casa, João.

c. João está vendendo a casa.

Contudo, Cruse (1973) assume que o teste para os verbos de ação não é satisfatório, pois não detecta agentividade em ações involuntárias. Por exemplo:

(4) a. João virou o balde acidentalmente.

b. ? Vire o balde acidentalmente, João.

c. ? João está virando o balde acidentalmente.

Em (4), o teste do imperativo e do progressivo não consegue captar o agentivo em ação involuntária.

Chafe (1970:98-99) propõe outros testes para detectar estados, processos e ações. Com a pergunta "O que aconteceu?", podemos distinguir estado de não-estado. Veja-se:

(5) O que aconteceu?

a. ? A madeira está seca. ${ }^{7}$

b. José morreu.

c. Maria cantou.

A oração (5a) não serve como resposta para a pergunta “O que aconteceu?". Isso ocorre porque nessa oração tem-se um não-evento. Isto é, a madeira está em um certo estado ou condição. O verbo está especificado como estado e é acompanhado por um nome que é seu Paciente/Objeto. As orações (5b) e (5c) servem como resposta a "O que aconteceu?" ou "O que está acontecendo?", pois um não-estado é um acontecimento, um evento.

${ }^{6}$ Segundo Cruse (1973), verbos de estado ou processuais podem, dependendo do contexto, ser considerados agentivos. Veremos essa questão mais adiante.

${ }^{7}$ Chafe (1970) usa o asterisco (*) para indicar agramaticalidade da oração. Preferimos, porém, seguir com a interrogação proposta por Cruse (1973). 
Cadernos de Estudos Lingüísticos 50(2) - Jul./Dez. 2008

Chafe (1970:100) estende o teste para diferenciar processo de ação. As orações classificadas como ações servem como resposta à questão "O que $\mathrm{N}$ fez?" ou "O que N está fazendo?" em que N é um nome. Veja-se:

(6) $\mathrm{O}$ que $\mathrm{N}$ fez?

a. Maria cantou.

b. ? José morreu.

A oração (6a) responde a pergunta "O que $\mathrm{N}$ fez?" ao passo que (6b) não. Por outro lado, os processos servem como resposta à questão "O que aconteceu a N?":

(7) O que aconteceu a N?

a. José morreu.

b. ? Maria cantou.

A oração (7a) é considerada processo, pois serve como resposta à pergunta "O que aconteceu a N?" ao passo que (7b) não.

Halliday (1968:196), citado por Cruse (1973), utilizou testes similares para identificar a do-clause ${ }^{8}$. Considerem-se as orações abaixo:

(8) a. João empurrou Bill.

b. O vaso quebrou.

De acordo com Halliday, (8a) é uma do-clause porque "O que o João fez foi empurrar Bill" é preferível a "O que aconteceu a João foi que ele empurrou Bill". Por outro lado, (8b) é uma happen-clause porque "O que aconteceu ao vaso foi que ele quebrou" é preferível a "O que o vaso fez foi quebrar".

Portanto, os verbos/predicadores ou as orações em geral são classificados em estados, processos ou ações. Os verbos ou as orações de estado são detectados quando não servem como resposta à questão "O que aconteceu?", pois não são eventos. Os processos são verbos/predicadores ou orações de eventos não-agentivos que são identificados pela questão "O que aconteceu a N?". E as ações são verbos/ predicadores ou orações agentivos que são captados pela pergunta "O que $\mathrm{N}$ fez?".

\subsection{O Modelo Semântico-Pragmático Utilizado}

O modelo utilizado por Nicolacópulos et al (1997), inicialmente, amparou-se nos modelos semânticos de Fillmore (1968, 1977), Chafe (1970), Anderson (1971) e Cook $(1979,1989)$. Posteriormente, com o objetivo de ampliar as perspectivas de análise,

${ }^{8} \mathrm{O}$ termo $\mathrm{d} o$-clause refere-se às orações agentivas e happen-clause às orações processuais na teoria apresentada por Halliday (1968). 
CONCEIÇÃO \& NICOLACÓPULOS - Causativização de predicadores estáticos...

esse modelo apresentou algumas modificações. Ele é um modelo não-localista ${ }^{9}$ e a estrutura profunda é semântico-sintática, isto é, os papéis temáticos ou casos são paralelos às funções sintáticas.

Seu sistema casual compõe-se de oito casos: agentivo, experienciador, benefactivo, objeto, locativo, temporal, comitativo e holístico. O caso agentivo expressa ação; o experienciador exprime sensação, emoção, cognição; o benefactivo denota posse, poder, ganho, propriedade; o objeto expressa o que está sendo descrito, quando temos um verbo de estado e é o que sofre mudança de estado, quando temos um processo; o locativo expressa localização; o caso temporal denota tempo cronológico; o comitativo expressa companhia e o caso holístico exprime a totalidade, o todo.

Este modelo ainda prevê a não-obrigatoriedade do caso objeto, em oposição a Cook (1989). Admite também a possibilidade de ocorrência de casos considerados mutuamente excludentes. É o que acontece, por exemplo, com o verbo passar, que permite os casos Le T, ambos proposicionais, como em "Jeffrey passou terça-feira à tarde na praia" (FILLMORE 1971:51). Esse tipo de ocorrência encontra suporte na adaptação da noção de cenas de Fillmore (1977), em que são colocados em perspectiva os elementos selecionados pelo falante, ficando os demais no background.

Os casos podem aparecer parcial ou totalmente não-manifestos na estrutura sintática da oração. Os casos parcialmente não-manifestos denominam-se casos apagáveis e os totalmente não-manifestos em co-referenciais e lexicalizados.

O modelo ainda considera que os casos estão em uma relação de associação com o verbo e não em relação de dependência. Dessa forma, Nicolacópulos et al. (1997:208) afirmam que "o verbo refletirá a soma desta interação e da(s) significação(ões) espraiada(s) pelo enunciado produzido em contexto."

Em suma, este modelo semântico-pragmático amplia os domínios das teoria de casos "a fim de que efetivamente abrigue as nuanças de sentido que se espraiam no contexto da língua em uso..." (OLIVEIRA 1999:71), expandindo as perspectivas de análise.

\section{OAGENTIVO}

Considere-se a noção de agentivo (semântico) com a de sujeito (sintático), de acordo com Marques (1999:119), levando em conta os argumentos relacionados aos predicadores, proposto por Fillmore (1968):

\footnotetext{
${ }^{9}$ A vertente não-localista compreende os casos básicos: A (agentivo) e O (objetivo), e os nãobásicos: E (experienciador), B (benefactivo), L (locativo), T (tempo); a vertente localista utiliza-se, de maneira geral, de cinco casos: dois básicos (A, O) e três não-básicos (locativo, origem e meta) que se dividem em locativos concretos (espaciais) e abstratos (os não-básicos da vertente não-localista).
} 
(9)
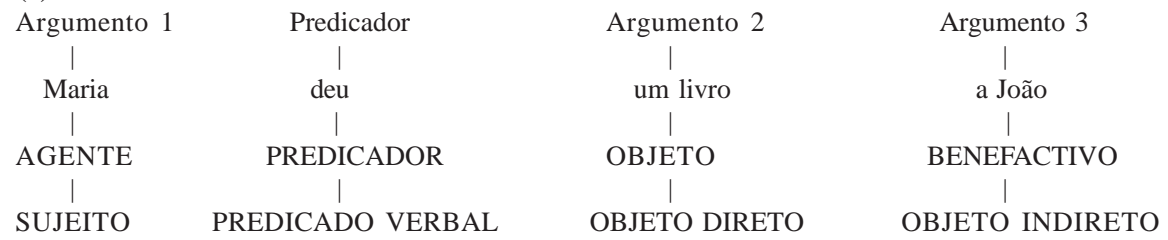

O predicado daré um verbo de três lugares. A ele estão relacionados os argumentos Maria, um livro e a João. Esses elementos recebem "rótulos" semânticos (agentivo, objeto e benefactivo) e sintáticos (sujeito, objeto direto e objeto indireto), respectivamente. Porém, não existe uma relação linear entre a noção de agentivo e a de sujeito. Considere-se (10): (10) Um livro foi dado a João (por Maria).

Em (10), semanticamente, um livro tem papel ou caso de objeto, a João tem caso benefactivo e por Maria tem caso agentivo. Sintaticamente, porém, um livro é o sujeito da oração, $a$ João é objeto indireto e por Maria é agente da passiva.

Lyons (1979:370) argumenta que a agentividade está relacionada à concepção de transitividade. $\mathrm{O}$ termo transitivo sugere que o efeito de ação expressa pelo verbo passa do agentivo para o paciente. Veja-se:

(11) Carlos matou João.

Matar é um verbo transitivo porque a ação referida passa de Carlos para João. Porém, nem sempre o verbo transitivo expressa agentividade:

\section{(12) Jonas ouve Maria.}

Nesta oração, há as mesmas relações sintáticas (sujeito e objeto) apresentadas em (11). Ouvir é considerado transitivo, embora, neste caso, a ação, se é que existe, está em sentido contrário. Cabe notar que ouvir não é totalmente paralelo a matar. Ele é um verbo estático, ao passo que matar expressa ação.

Pode-se então dizer que o sujeito de uma oração pode encerrar vários casos: agentivo (A), experienciador (E), benefactivo (B), objeto (O), locativo (L) etc. Conforme Cook (1989), essa ordem de casos deve ser seguida, isto é, se há caso agentivo, este vai para a posição sujeito; na sua ausência, o caso experienciador ocupa a posição sujeito e assim sucessivamente. O caso agentivo também pode ser co-referente com E, B, O, L. Nicolacópulos e Zucco (1996) propõem que ao agentivo sejam co-referentes o caso holístico, como proposto por Flores (1994), e o caso comitativo.

O caso agentivo, porém, apresenta nomenclaturas diferentes. Fillmore (1968) o denomina agentivo; Anderson (1971) o nomeia ergativo. As definições também apresentam diferenças. Fillmore (1968:299) define caso agentivo como "o instigador da ação verbal identificada pelo verbo, instigador esse percebido tipicamente como ser animado" 10 .

${ }^{10}$ Em nota de rodapé, Fillmore (1968:299) diz que o termo "tipicamente" expressa sua percepção de que há contextos em que o agentivo é ocupado por nome inanimado, como robô, por exemplo. 
CONCEIÇÃO \& NICOLACÓPULOS - Causativização de predicadores estáticos...

Anderson (1971) define ergativo como "o iniciador da ação associada ao verbo". Cook (1989:191) diz que agentivo "é o caso requerido por um verbo de ação. Embora o agente seja o performador tipicamente animado da ação verbal, nomes inanimados também podem ocorrer como agentes."

A definição de Fillmore (1968) apresenta problemas com relação ao traço [+animado] do agentivo. O próprio Fillmore (1971) reformulou essa posição, dizendo que não confundia mais restrições de [ \pm animado] com verdadeiras noções de caso. O fato é que não se deve definir caso em termos de restrições de seleção.

Cruse (1973:18) assume que o agentivo é um "subgrupo definido de agentivos [doers]". Há quatro traços semânticos distintos que indicam agentividade. São eles: o volitivo, o efetivo, o iniciativo e o agentivo. Neste trabalho, porém, será enfocado apenas o traço volitivo $^{11}$.

O traço volitivo (= intenção) está presente quando há um ato de intenção implícita ou explicitamente:

(13) Cristo morreu para nos salvar de nossos pecados.

Em (13), a intenção está explícita através da oração final "para nos salvar de nossos pecados." Gruber (1967), citado por Cruse (1973), usa o critério de modificabilidade para detectar a volitividade. Segundo o autor, orações que começam com in order to (com o objetivo, a fim de) são testes de volitividade. Em orações desse tipo, não é possível inserir o advérbio acidentalmente:

(14) ? João pisou acidentalmente no brinquedo, com o objetivo de castigar a criança.

O teste do imperativo, usado por Anderson (1971) como teste para os ergativos, também é um teste de volitividade. Os imperativos também não aceitam o modificador acidentalmente:

(15) ? Vire o balde acidentalmente.

Gruber (1967), citado por Cruse (1973), utiliza outro critério para detectar o volitivo. A modificabilidade por carefully (cuidadosamente) mostra a combinação entre volitivo e agentivo $^{12}$ :

(16) a. ? João caiu da janela cuidadosamente.

b. João empurrou a porta cuidadosamente.

Em (16a), o advérbio cuidadosamente detecta a não-intenção de João. Porém, em (16b), o advérbio faz a combinação entre o traço agentivo, um dos traços semânticos captados por Cruse (1973), e a intenção (volição).

\footnotetext{
${ }^{11}$ Em estudo semelhante, Langacker (1975: 366) chama volição de intenção.

${ }^{12}$ Remarque-se que, embora agentividade e volitividade freqüentemente co-ocorram, eles são traços independentes.
} 
Cadernos de Estudos Lingüísticos 50(2) - Jul./Dez. 2008

Em suma, os testes aplicados por Cruse para detectar intenção servirão como base para este trabalho. Os enunciados com verbos/predicadores estáticos e processuais serão analisados e, quando apresentarem o fator intenção, serão considerados causativizados, como será visto na seção 4.1.

\section{O CORPUS ${ }^{13}$}

O corpus é composto por 31.692 enunciados jornalísticos. Desses, 29.342 são verbos/ predicadores estáticos e 2.350 processuais. No entanto, dos 29.342 verbos/predicadores estáticos, 7.876 se tornaram processuais. Nesse caso, tais verbos foram desconsiderados para a análise da causativização, já que o enfoque está sobre os verbos/predicadores basicamente estáticos e processuais. Assim, o número total de enunciados passou para 23.816. A coleta de dados foi feita através do software "Analing", produzido pelo Laboratório de Circuitos e Processamento de Sinais - LINSE da UFSC. O software faz a coleta dos enunciados por períodos (de ponto a ponto). A busca dos dados é feita a partir do verbo (radical mais desinências). O software também referencia o enunciado, isto é, dá a página e a data em que o enunciado foi encontrado.

Os verbos analisados, alguns dos mais recorrentes em textos jornalísticos, são: amar, conhecer, entender, ignorar, saber, ser, estar, ter, ver (verbos estáticos) e acordar, aprender, cair, crescer, dormir, esquecer, ganhar, morrer, vencer (verbos processuais). Além desses verbos/predicadores, foram analisados os verbos pertencer (estático) e durar (processual), não tão recorrentes em textos jornalísticos, mas que apontavam um alto índice de resistência à causativização.

Foram coletados somente os enunciados com os verbos na $1^{\mathrm{a}} \mathrm{e} 3^{\mathrm{a}}$ pessoas do singular e plural no presente, pretérito perfeito e futuro do indicativo, no presente do subjuntivo e no imperativo. As formas ditas nominais, infinitivo e gerúndio também foram computadas.

Com mais de 50 mil enunciados coletados, foram desconsiderados aqueles que apresentavam voz passiva, como em:

(17) "É comum, então, que operem uma espécie de curto-circuito: Oswald Spengler foi esquecido com a rapidez da catástrofe, em direção à qual, segundo sua própria teoria, caminhava o curso do mundo."(Folha de São Paulo, 21/12/97, pg. 5-3)

(18) "Assis teria ficado irritado porque Silvéria estava presente sem ter sido convidada para o batizado e expulsou-a da catedral enquanto celebrava a cerimônia." (Folha de São Paulo, 11/12/97, pg. 3-9)

Foram analisados os verbos/predicadores estáticos e processuais tanto em orações principais como (19) quanto em encaixadas como (20):

\footnotetext{
${ }^{13}$ Agradecemos a Suzana Rocha por se dispor a ajudar na coleta dos dados.
} 
CONCEIÇÃO \& NICOLACÓPULOS - Causativização de predicadores estáticos...

(19) "Ninguém ignora que a essa série de descuidos elementares e cotidianos somam-se problemas estruturais, tais como a falta de verbas e a superlotação.” (Folha de São Paulo, 02/12/97, pg. 1-2)

(20) "Técnico Zagallo, que errou na Copa de 74 ao ignorar os holandeses, não costuma assistir muito aos jogos dos adversários.” (Folha de São Paulo, 02/12/97, pg. Especial-4)

\section{ANÁLISE DOS DADOS}

Quanto à classificação dos verbos/predicadores em estados ou processos, escolheuse como critério para identificá-los o teste de perguntas: “O que aconteceu?" para identificar os verbos estáticos e "O que aconteceu a N?" para identificar os verbos processuais. Por exemplo, a pergunta “O que aconteceu?” diferencia estado de não-estado:

(21) "Entretanto, os investidores brasileiros já conhecem bem esse mecanismo; o BNDES utiliza-o com freqüência, e existem hoje sofisticados modelos matemáticos para estimar o preço dessas opções. (Folha de São Paulo, 03/12/97, pg. 2-2)

(22) "Mail and Guardian", um dos mais influentes jornais do país, resumiu assim a postura dos sul-africanos frente a Mbeki: "Estamos prestes a ser governados por um homem que não conhecemos". (Folha de São Paulo, 27/12/97, pg. 1-11)

Os enunciados (21) e (22) não servem como resposta à questão "O que aconteceu?", portanto são estados.

Todavia, a questão "O que aconteceu?" ou "O que está acontecendo?” permite respostas como:

(23) "Os moradores acabam conhecendo a gente e passam a atuar em parceria, indicando locais perigosos e pessoas suspeitas, disse o soldado Jairo Gomes, 31." (Folha de São Paulo, 01/12/97,pg. 3-9)

(24) "Eles se conheceram há 14 anos no Bar e Restaurante La Mar, o bar da Cristina, um restaurante de pratos comerciais localizado no centro de Curitiba." (Folha de São Paulo, 07/ 12/97,pg. 11)

(25) "Aos 16 anos, ela contraiu Aids do primeiro namorado, que conheceu durante uma viagem de navio.” (Folha de São Paulo, 29/12/97, pg. 6-4)

Por este teste, os enunciados (23) a (25) são de não-estado. Mas seriam processuais ou agentivos? Esses enunciados servem como resposta à questão "O que aconteceu a N?", mas não a "O que N fez?”. Assim, são classificados como processuais.

\subsection{A Causativização no Português Brasileiro}

Parsons (1994), assim como McCawley (1976), Cook $(1979,1989)$ entre outros, propõe que sejam consideradas orações agentivas aquelas que apresentam, em sua estrutura 
Cadernos de Estudos Lingüísticos 50(2) - Jul./Dez. 2008 profunda, $D O$ (fazer), CAUSE (causa) e BECOME (tornar-se). Assim, para a oração $O$ palhaço assustou a criança, a estrutura profunda seria:

(26) $\left[_{\mathrm{S}}\left[_{\mathrm{NP}} \mathrm{O}\right.\right.$ palhaço $]\left[_{\mathrm{V}}\right.$ fez $\left[\mathrm{V}\right.$ ficar $\left[_{\mathrm{ADJ}}\right.$ assustada $\left[_{\mathrm{NP}}\right.$ a criança $\left.\left.\left.\left.\left.]\right]\right]\right]\right]\right]$

O NP o palhaço é então agentivo. Da mesma forma, o fator intenção - que está no âmbito da pragmática ${ }^{14}$, quando acrescido aos predicadores estáticos e processuais, insere o predicado abstrato CAUSE (CAUSA) a estes verbos, causativizando-os. Veja-se o esquema abaixo:

(27) Estado/Processo + intenção = ação

A intenção é um traço pragmático ligado ao sujeito-enunciador que leva em consideração o conhecimento (supostamente compartilhado com o interlocutor). Nos textos jornalísticos analisados, foi detectada a presença do fator intenção em verbos/predicadores como querer, dever / ter (no sentido de obrigação), procurar, fingir, decidir, necessitar, tentar, convencer, buscar e esperar. Considerem-se os enunciados abaixo:

(28) "Havia, claramente, duas correntes entre os cristãos: uma que procurava aprender o máximo sobre e com o islamismo (à qual pertencia) e outra que adotara uma postura de confrontação e encarava tudo como ofensa pessoal e discriminação religiosa." (Folha de São Paulo, 24/12/97, pg. 1-12)

(29) "A Tunísia, a mais fraca do (sic) grupo, cresce em importância justamente por poder decidir quem cai com ela na primeira fase: Romênia ou Colômbia." (Folha de São Paulo, 07/ 12/97, pg. 4-12)

(30) "Labaki preferiu ignorar a notícia, embora o nosso tenha sido o primeiro filme brasileiro a entrar em circuito comercial na Itália desde "Eles Não Usam Black-Tie". (Folha de São Paulo, 22/12/97, pg. 5-4)

(31) "Um outro local privilegiado de escuta são as barbearias ou os assentos de canto nos vagões dos trens municipais, porque em ambos os casos é possível fingir dormir, tornar-se mais ou menos invisível, e assim prestar atenção à conversa ao redor." (Folha de São Paulo, 28/12/97, pg. 5-2)

(32) "Numa sociedade que pretende ser econômica e socialmente moderna, a realidade mostrada por IBGE e Unicef merece muita reflexão." (Folha de São Paulo, 05/12/97, pg. 32)

Os verbos/predicadores sublinhados nos enunciados (28) a (32) indicam intenção do sujeito-enunciador. Eles, por sua vez, influenciam os verbos analisados, como aprender,

${ }^{14} \mathrm{O}$ termo pragmática assume, neste trabalho, uma dimensão enunciativa. A concepção de pragmática é estendida ao campo comunicativo em uma perspectiva interacional. Segundo Oliveira (1999:27), “A questão do sujeito é posta como uma relação entre interlocutores considerados usuários, que usam a linguagem como instrumento para realizar algo, para manifestar intenções - a enunciação como ato de dizer algo para alguém." 
CONCEIÇÃO \& NICOLACÓPULOS - Causativização de predicadores estáticos...

cair, ignorar, dormir e ser. Por exemplo, em (31), fingir, que indica intenção, influencia dormir, verbo/predicador basicamente processual. Dormir, com o traço de intenção manifesto por fingir, passa a ser causativizado. Ao ser causativizado, passa a distribuir o caso agentivo, caso de verbos/predicadores de ação.

Os sintagmas nominais que indicam intenção como objetivo de, vontade de também afetam os verbos/predicadores estudados:

(33) "Além disso, policiais femininas à paisana e em carros particulares circulam pelas mesmas ruas, com o objetivo de cair nas garras dos criminosos e prendê-los." (Folha de São Paulo, 14/12/97, pg. 3-3)

(34) "Mas os suecos, com menos estrelas, mostraram mais consistência e vontade de vencer." (Folha de São Paulo, 01/12/97, pg. 4-8)

Sintagmas como objetivo de, vontade de acabam interferindo no sentido do verbo.

$\mathrm{O}$ verbo/predicador fazer também interfere no sentido básico ${ }^{15}$ dos verbos estáticos e processuais analisados. Considerem-se:

(35) “A criação da chamada frota verde é apenas o primeiro passo para ressuscitar o Proálcool (Programa Nacional do Álcool) e fazer crescer a produção de veículos movidos a álcool.” (Folha de São Paulo, 06/12/97, pg. 1-4)

(36) "Não pode ser coincidência o fato de a versão original do rouba, mas faz pertencer a um legítimo paulista, Adhemar de Barros." (Folha de São Paulo, 18/12/97, pg. 1-2)

(37) "O texto de Duby, propriamente dito, traz a marca do grande historiador, com sua insólita capacidade de organização do material histórico em uma prosa que faz quase esquecer, por sua fluidez, os estratos diversos de erudição sobre o qual repousa." (Folha de São Paulo, 13/12/97, pg. 10)

(38) "Quando o poeta banha-se ao sol gramatical, ou observa o vôo circunflexo de uma ave, já faz ver até que ponto a experiência é presa da língua." (Folha de São Paulo, 07/12/97, pg. 4-2)

Assim, os verbos/predicadores crescer, pertencer, esquecer e ver, como os apresentados nos enunciados (35) a (38), deixam de ser basicamente estado e processo e passam a ser causativizados.

O teste do imperativo também é aplicável aos verbos/predicadores estáticos e processuais em análise. Considerem-se:

(39) “Cunhada do empresário Joaquim Justo dos Santos, (sic) apresentou cópia do contrato social da empresa Jussantos Administração de Bens e Negócios Ltda, em que o nome e os dados pessoais de Ascenção Amarelo Martins aparecem com tipo de impressão e até o

${ }^{15}$ De acordo com Oliveira (1999:112), o sentido básico "funciona como aquele sentido primeiro, que já está incorporado ao mundo da cultura e que viabiliza investimentos em direção a novos efeitos de sentido (...)" 
Cadernos de Estudos Lingüísticos 50(2) - Jul./Dez. 2008

alinhamento diferentes dos demais sócios (veja quadro ao lado)". (Folha de São Paulo, 01/12/97, pg. 1-10)

(40) "Entenda, de uma vez por todas, que minha tese nunca foi a de comprovar se Aranha era ou não anti-semita (essa preocupação é exclusivamente sua), e sim a de analisar o projeto político anti-semita do governo Vargas - que, para ser posto em prática, valeu-se de homens ilustres, promotores de uma cultura política que, durante anos, deixou milhares de judeus entregues ao terror nazista." (Folha de São Paulo, 29/12/97, pg. 1-3)

(41) "Para beber, esqueça o álcool, proibido e reprimido com açoitamento." (Folha de São Paulo, 14/12/97, pg. 28 a 32)

(42) "Acorda, governo, e vai trabalhar fiscalizando a picaretagem filantrópica." (Folha de São Paulo, 07/12/97, pg. 2-2)

(43) "Conheça iniciativas da sociedade civil para ajudar brasileiros carentes, e veja os cuidados a tomar antes de fazer doações." (Folha de São Paulo, 18/12/97, pg. 1-1)

(44) "Saiba quais são os auxílios que o trabalhador pode receber nesse caso." (Folha de São Paulo, 21/12/97, pg. 6-13)

(45) "Para ecoar as palavras de Gandhi: Seja a mudança que você deseja ver no mundo." (Folha de São Paulo, 10/12/97, pg. 1-3)

Dos verbos/predicadores analisados, quase todos apresentam a forma imperativa. Até mesmo os verbos/predicadores que se apresentam com menos freqüência causativizados, como ser $(4,17 \%)$, conforme se observará adiante, admite imperativo. O imperativo é um bom teste para detectar intenção, porque não permite ações involuntárias, como proposto por Cruse (1973):

(46) ? "Saiba [acidentalmente] ${ }^{16}$ quais são os auxílios que o trabalhador pode receber nesse caso." (Folha de São Paulo, 21/12/97, pg. 6-13)

Outra forma de se detectar o fator intenção nos enunciados é aplicar o teste de Gruber (1967), citado por Cruse (1973). Segundo o autor, modificadores como in order to (com o objetivo de, a fim de) são testes para detectar intenção. Observem-se os enunciados abaixo:

(47) "A chegada do El Niño significa que nasceu um Deus, morreu para nos salvar etc." (Folha de São Paulo, 29/12/97, pg. 4-7)

(48) "O adolescente cinéfilo que trabalhava no verão para estar em Buenos Aires no inverno e frequientar os cinemas da capital considerava Mar del Plata um ambiente estreito para seus sonhos." (Folha de São Paulo, 09/12/97, pg. 4-3)

(49) "O privilégio fez com que pudéssemos passar os últimos três anos experimentando todos os atacantes tapuias com mais de $12 \mathrm{~kg}$, para ver quem vai jogar ao lado do Ronaldinho." (Folha de São Paulo, 10/12/97, pg. 3-2)

(50) "Um churrasco feito na cobertura envidraçada de um apartamento é a comparação adequada para se entender o que a humanidade está fazendo com o planeta Terra com o chamado aquecimento global." (Folha de São Paulo, 07/12/97, pg. 1-28)

\footnotetext{
${ }^{16}$ Grifo nosso.
} 
CONCEIÇÃO \& NICOLACÓPULOS - Causativização de predicadores estáticos...

(51) "Elas aprenderam a lutar e a dar tiros exatamente para nunca ter de bater no agressor ou atirar nele." (Folha de São Paulo, 14/12/97, pg. 3-4)

A presença de oração adverbial final manifesta por para indica intenção. Esse elemento afeta os verbos/predicadores analisados, como morrer, estar, ver, entender e aprender. Assim, os verbos/predicadores basicamente estáticos (estar, ver e entender) e processuais (morrer e aprender) passam a ser causativizados.

No entanto, não se pode generalizar que todas as orações adverbiais finais encerram intenção. Segundo o corpus analisado, existem alguns enunciados em que a presença de orações adverbiais finais não apresenta intenção, como por exemplo, no enunciado (52):

(52) "Anotei os males que curava ou aliviava: Palpitações do coração, falta de ar, sobressaltos no sono, aperto e agonia na cabeça, sufocações, arrotos, boca amarga, ventosidades, enjôos em horas importunas (havia então horas oportunas para se ter enjôo), dores no peito e nas cadeiras, tremuras e excitações (era um tempo deveras excitante), suores frios, desmaios súbitos [...]".

O enunciado (52) apresenta uma oração adverbial final que não tem intenção. Se assim, o verbo/predicador ter (estático), mantém seu sentido basicamente estático.

Outra forma para se detectar a intenção está relacionada única e exclusivamente à interpretação ${ }^{17}$. Assim, nos enunciados, em que não há nenhum elemento lingüístico que marque intenção, pode-se usar o advérbio deliberadamente para indicar ação voluntária. Vejam-se:

(53) "Dívida - O Senado aprovou ontem a rolagem de R\$ 1,073 bilhão de títulos públicos do Estado de São Paulo, ignorando [deliberadamente] ${ }^{18}$ parecer do BC que apontava o descumprimento da Lei Camata - que fixa em $60 \%$ do orçamento o limite de gastos com pessoal." (Folha de São Paulo, 10/12/97, pg. 1-5)

(54) "Os vereadores ignoraram [deliberadamente] parecer técnico dos auditores do Tribunal de Contas do Município (TCM), que recomendavam a rejeição, e optaram por abonar a contabilidade do último ano da gestão de Paulo Maluf." (Folha de São Paulo, 19/12/97, pg. 3-3)

(55) "Na empresa de animação Brasil Promoshow, o Papai Noel pode chegar de carro, charrete, jipe, helicóptero ou até mesmo cair [deliberadamente] de pára-quedas no meio do seu quintal." (Folha de São Paulo, 07/12/97, pg. 90 a 91)

Como observado em (53), (54) e (55), nenhum elemento lingüístico detecta intenção. Mas a introdução do advérbio deliberadamente, que não faz parte do texto original,

${ }^{17}$ Oliveira (1999:113) afirma que a interpretação "deflagra o cotejo entre o que é produzido e a intenção que subjaz a essa produção."

${ }^{18}$ Grifo nosso. 
Cadernos de Estudos Lingüísticos 50(2) - Jul./Dez. 2008

indica ação voluntária desses verbos. Assim, os verbos/predicadores perdem o seu sentido básico, estático ou processual, e passam a ser causativizados.

Em suma, os elementos que tornam detectável a intenção do sujeito-enunciador são:

- verbos/predicadores: querer, dever / ter (no sentido de obrigação), procurar, fingir, decidir, tentar etc;

- sintagmas como objetivo de e vontade de;

- teste do imperativo, pois não se pode ter ações como involuntárias. Todas as ações seriam voluntárias;

- advérbios como cuidadosamente, deliberadamente;

- orações adverbiais finais.

\subsection{Os Resultados}

De modo geral, causativizaram-se $9,04 \%$ de verbos/predicadores estáticos e $14,64 \%$ processuais. A análise dos verbos/predicadores estáticos permitiu verificar que eles podem se tornar processuais, como em:

(56) "Basta lembrar o caso da Argentina, que também chegou aos trancos e barrancos à Copa de 94 e acabou sendo a grande sensação da primeira fase do torneio, só tendo sido eliminada porque dependia muito, técnica e moralmente, de seu principal astro, Diego Maradona, afastado por doping." (Folha de São Paulo, 02/12/97, pg. Especial12)

(57) "Se você fizer com um número de clubes que dê motivação para a competição, com qualidade, todos os jogos vão ter muitos torcedores, e vai ser um campeonato bastante motivadore." (Folha de São Paulo, 02/12/97, pg. 3-11)

(58) “* Fui vítima de um acidente de trânsito em julho do ano passado.” (Folha de São Paulo, 21/12/97,pg. 1-2)

Para se ter idéia do comportamento dos verbos analisados em relação à transformação de verbos/predicadores basicamente estáticos em processuais e viceversa, elaboraram-se as Tabelas 2 e 3: 
CONCEIÇÃO \& NICOLACÓPULOS - Causativização de predicadores estáticos...

Tabela 2 - Mudança de sentido básico de verbos/predicadores estáticos

\begin{tabular}{|l|c|c|c|c|c|}
\hline \multirow{2}{*}{ VERBOS } & \multicolumn{2}{|c|}{ ESTADO } & \multicolumn{3}{c|}{ PROCESSO } \\
\cline { 2 - 6 } & Aplicação & $\begin{array}{c}\text { Freqüência } \\
\text { de } \\
\text { Ocorrência }\end{array}$ & Aplicação & $\begin{array}{c}\text { Freqüência } \\
\text { de } \\
\text { Ocorrência }\end{array}$ & Total \\
\hline Entender & 169 & $100 \%$ & 00 & $0 \%$ & 169 \\
\hline Ignorar & 09 & $100 \%$ & 00 & $0 \%$ & 09 \\
\hline Pertencer & 108 & $97,30 \%$ & 03 & $2,7 \%$ & 111 \\
\hline Saber & 496 & $97,30 \%$ & 231 & $2,7 \%$ & 727 \\
\hline Amar & 36 & $90 \%$ & 04 & $10 \%$ & 40 \\
\hline Estar & 2713 & $84,23 \%$ & 508 & $15,77 \%$ & 3221 \\
\hline Ter & 4160 & $71,74 \%$ & 1639 & $28,26 \%$ & 5799 \\
\hline Ser & 11627 & $69,34 \%$ & 5142 & $30,66 \%$ & 16769 \\
\hline Conhecer & 128 & $64,65 \%$ & 70 & $35,35 \%$ & 198 \\
\hline Ver & 79 & $22,07 \%$ & 279 & $77,93 \%$ & 358 \\
\hline TOTAL & 19525 & $71,26 \%$ & 7876 & $28,74 \%$ & 27401 \\
\hline
\end{tabular}

Como pode ser observado pela Tabela 2, os verbos/predicadores estáticos se mantêm, em sua grande maioria, em seu sentido básico, ou seja, estático (71,26\%). Os verbos/predicadores entender e ignorar não apresentaram enunciados processuais. Por outro lado, o verbo/ predicador ver foi o único com sentido básico estático que apresentou mais ocorrências como processual. Das 358 ocorrências com este verbo, 79 ocorreram como estáticas $(22,07$ $\%$ ) e 279 como processuais $(77,93 \%)^{19}$. Os verbos/predicadores processuais, por sua vez, não apresentaram ocorrências como estáticos, como mostra a Tabela 3:

Tabela 3 - Mudança de sentido básico de verbos/predicadores processuais

\begin{tabular}{|l|c|c|c|c|c|}
\hline \multirow{2}{*}{ VERBOS } & \multicolumn{2}{|c|}{ ESTADO } & \multicolumn{2}{c|}{ PROCESSO } & \multirow{2}{*}{ Total } \\
\cline { 2 - 5 } & Aplicação & $\begin{array}{c}\text { Freqüência } \\
\text { de } \\
\text { Ocorrência }\end{array}$ & Aplicação & $\begin{array}{c}\text { Freqüência } \\
\text { de } \\
\text { Ocorrência }\end{array}$ & \\
\hline Morrer & 0 & $0 \%$ & 352 & $98,05 \%$ & 359 \\
\hline Cair & 0 & $0 \%$ & 555 & $97,20 \%$ & 571 \\
\hline Durar & 0 & $0 \%$ & 117 & $96,70 \%$ & 121 \\
\hline Crescer & 0 & $0 \%$ & 383 & $89,49 \%$ & 428 \\
\hline Acordar & 0 & $0 \%$ & 25 & $86,20 \%$ & 29 \\
\hline Ganhar & 0 & $0 \%$ & 112 & $78,32 \%$ & 143 \\
\hline Vencer & 0 & $0 \%$ & 285 & $75,40 \%$ & 378 \\
\hline Dormir & 0 & $0 \%$ & 47 & $69,12 \%$ & 68 \\
\hline Aprender & 0 & $0 \%$ & 98 & $60,50 \%$ & 162 \\
\hline Esquecer & 0 & $0 \%$ & 32 & $35,16 \%$ & 91 \\
\hline TOTAL & 0 & $0 \%$ & 2006 & $85,36 \%$ & 2350 \\
\hline
\end{tabular}

${ }^{19}$ Os verbos/predicadores estáticos que se tornaram processuais, num total de 7.876, foram desconsiderados para a análise de causativização, já que o nosso objetivo era observar apenas o processo de causativização em verbos basicamente estáticos e processuais. Assim, nosso número total de enunciados passou dos 31.692 iniciais para 23.816 .

${ }^{20}$ A diferença entre os dados totalizados (2.006 para 2.350) referem-se aos verbos/predicadores que mudaram do sentido básico processual para o agentivo pelo processo de causativização. 
Cadernos de Estudos Lingüísticos 50(2) - Jul./Dez. 2008

Pela Tabela 3, pode-se observar que os verbos processuais mantêm-se em seu sentido básico. Por outro lado, observa-se, pelas Tabelas 4 e 5, que a causativização ocorre tanto nos verbos/predicadores estáticos quantos nos processuais. Considerem-se primeiramente os estáticos:

Tabela 4 - Verbos/predicadores estáticos causativizados

\begin{tabular}{|l|c|c|c|}
\hline \multirow{2}{*}{ ESTADO } & \multicolumn{2}{|c|}{ CAUSATIVIZAÇÃO } & \multirow{2}{*}{ Total } \\
\cline { 2 - 3 } & Aplicação & $\begin{array}{c}\text { Freqüência } \\
\text { de } \\
\text { Ocorrência }\end{array}$ & \\
\hline Ver & 432 & $84,54 \%$ & 511 \\
\hline Ignorar & 36 & $80 \%$ & 45 \\
\hline Conhecer & 91 & $41,55 \%$ & 219 \\
\hline Entender & 105 & $38,32 \%$ & 274 \\
\hline Saber & 170 & $25,52 \%$ & 666 \\
\hline Amar & 11 & $23,40 \%$ & 47 \\
\hline Ter & 470 & $10,15 \%$ & 4630 \\
\hline Estar & 119 & $4,21 \%$ & 2832 \\
\hline Ser & 506 & $4,17 \%$ & 12133 \\
\hline Pertencer & 01 & $0,92 \%$ & 109 \\
\hline TOTAL & 1941 & $9,04 \%$ & 21466 \\
\hline
\end{tabular}

Pela Tabela 4, tem-se 9,04\% de suas ocorrências causativizadas entre os estáticos. Neste caso, pode-se constatar que há uma alta frequiência de causativização de ver $(84,58 \%)$ e ignorar $(80 \%)$, sendo o verbo/predicador pertencer $(0,92 \%)$ o que apresenta maior resistência à causativização. Os verbos/predicadores processuais que se causativizam são apresentados na Tabela 5. Nesta tabela, percebe-se que os processuais apresentam-se causativizados em 14,64\% das ocorrências.

Tabela 5 - Verbos/predicadores processuais causativizados

\begin{tabular}{|l|c|c|c|}
\hline \multirow{2}{*}{ PROCESSO } & \multicolumn{2}{|c|}{ CAUSATIVIZAÇÃO } & \multirow{2}{*}{ Total } \\
\cline { 2 - 3 } & Aplicação & $\begin{array}{c}\text { Freqüência } \\
\text { de } \\
\text { Ocorrência }\end{array}$ & \\
\hline Esquecer & 59 & $64,84 \%$ & 91 \\
\hline Aprender & 64 & $39,50 \%$ & 162 \\
\hline Dormir & 21 & $30,88 \%$ & 68 \\
\hline Vencer & 93 & $24,60 \%$ & 378 \\
\hline Ganhar & 31 & $21,68 \%$ & 143 \\
\hline Acordar & 04 & $13,80 \%$ & 29 \\
\hline Crescer & 45 & $10,51 \%$ & 428 \\
\hline Durar & 04 & $3,31 \%$ & 121 \\
\hline Cair & 16 & $2,80 \%$ & 571 \\
\hline Morrer & 07 & $1,95 \%$ & 359 \\
\hline TOTAL & 344 & $14,64 \%$ & 2350 \\
\hline
\end{tabular}


CONCEIÇÃO \& NICOLACÓPULOS - Causativização de predicadores estáticos...

Dos verbos/predicadores processuais, apresenta-se mais causativizado o verbo/predicador esquecer (64,84\%), seguido do verbo/predicador aprender com 39,50\% de ocorrências desse tipo. No entanto, o que menos apresenta causativização é morrer (1,95\%).

No Gráfico 1, é apresentada a comparação das ocorrências de causativização de verbos/ predicadores estáticos e processuais:

Gráfico 1 - Causativização nos verbos/predicadores estáticos e processuais

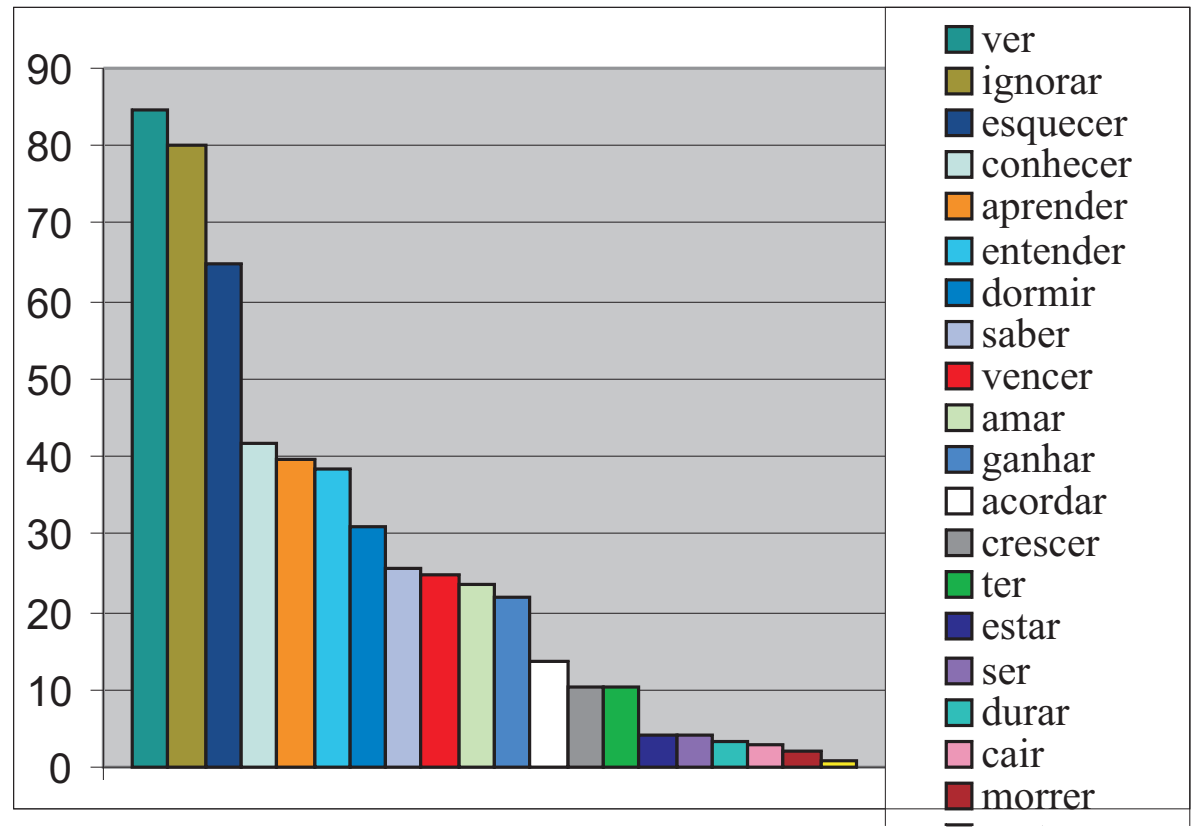

Destes resultados, não se pode fazer, porém, a previsão de que os verbos/predicadores processuais se causativizariam mais do que os estáticos. Principalmente porque o percentual total de causativização entre esses verbos é bastante próximo (14,64\% e 9,04\%, respectivamente). No entanto, os estáticos ver e ignorar apresentam um alto índice de causativização $(84,54 \%$ e 78,26\%, respectivamente). Entre os processuais tem-se o verbo/ predicador esquecer também com grande índice de causativização $(64,84 \%)$.

Desta análise, também se conclui que os estáticos pertencer, ser e estar e os processuais morrer, cair e durar apresentam os menores índices de causativização (abaixo de $5 \%$ de ocorrência, conforme Tabelas 5 e 6 ).

Assim, o que se pode constatar é que certos verbos possibilitam mais a causativização do que outros, sendo aqueles mais sensíveis ao traço intenção do que estes. Isto ocorre tanto para estáticos como para processuais. 
Cadernos de Estudos Lingüísticos 50(2) - Jul./Dez. 2008

\section{CONSIDERAÇÕES FINAIS}

A quantificação dos dados, em um total de 31.692 enunciados jornalísticos, possibilitou a constatação da hipótese do estudo: os verbos estáticos e processuais admitem causativização. Entre os verbos/predicadores estáticos, 9,04\% se causativizaram e entre os verbos/predicadores processuais, $14,64 \%$. O elemento principal que direcionou a análise foi o fator intenção.

Partindo-se do estudo de Cruse (1973) sobre o agentivo e levando-se em conta o traço semântico intenção (usado pelo autor como volitivo), percebeu-se que este elemento interfere na interpretação do verbo. Os verbos/predicadores estáticos e processuais podem se tornar de ação se a eles for acrescido o fator intenção.

Cruse (1973) aplica alguns testes para detectar intenção. O teste do imperativo, por exemplo, não é um bom teste para captar o agentivo, nos termos de Anderson (1971), porque não detecta ação involuntária. Porém, serve para captar a intenção do sujeitoenunciador. O imperativo não permite que advérbios como acidentalmente façam parte do enunciado.

$\mathrm{O}$ advérbio cuidadosamente acrescentado ao enunciado também detecta o fator intenção. Os enunciados que apresentam elementos como objetivo de, a fim de, para, também captam a intenção.

Este estudo pode constatar que no Português Brasileiro, a intenção se manifesta em enunciados de várias formas:

1. No imperativo, pois não é possível se ter ações involuntárias com ele;

2. Em verbos/predicadores como querer, dever / ter (no sentido de obrigação), procurar, fingir, decidir, necessitar, tentar, convencer, buscar, e esperar;

3. Nos sintagmas nominais como objetivo de e vontade de;

4. Em quase todas as ocorrências com oração adverbial final, exceto ocorrências do tipo (53), que remetem à leitura não-intencional;

5. Há enunciados que não apresentam nenhum elemento lingüístico que marque intenção, contudo, é possível detectá-la pelo contexto. $\mathrm{Na}$ análise proposta, acrescentou-se o advérbio deliberadamente para indicar ação voluntária.

Em suma, constatou-se que, dos vinte verbos/predicadores estáticos e processuais analisados, todos apresentaram-se causativizados. Isto aconteceu porque a eles foi acrescido o fator intenção. Pode-se dizer também que os verbos ver, ignorar e esquecer apresentam mais causativização e os verbos pertencer, ser, estar, morrer, cair e durar resistem muito mais a esse processo.

Finaliza-se concluindo que o estudo sobre causativização pode ser aprofundado. Fica, como proposta de estudo, analisar o comportamento das causativizações em cada campo semântico (básico, experimentativo, benefactivo, locativo, temporal, comitativo e holístico), levando-se em conta os casos semânticos. 
CONCEIÇÃO \& NICOLACÓPULOS - Causativização de predicadores estáticos... REFERÊNCIAS BIBLIOGRÁFICAS

ANDERSON, J. M. (1971). The Grammar of Case: Towards a Localistic Theory. Cambridge: Univerity Cambridge.

CD-Rom da Folha de São Paulo, 1997.

CHAFE, W. (1979). Significado e Estrutura Lingüística. Tradução de Maria Helena de Moura Neves, Odete G. Altmanm de Souza Campos e Sônia V. Rodrigues. RJ: Livros técnicos e científicos.

COOK, W. A. (1979). Case Grammar: development of the Matrix Model (1970-1978). Washington, D.C.: Georgetown University. (1989). Case Grammar Theory. Washington, D.C.: Georgetown University.

CRUSE, D. (1973). Some Thoughts on Agentivity. In: Journal of Linguistics, n. 9, p. 11-23.

FILLMORE, C. J. (1968). The Case for Case. In: Bach, E \& Harms, R. (eds.) Universals in Linguistic Theory. New York: Holt, Rinehart \& Winsto, p. 1-90.

(1971). Some Problems for Case Grammar. In: Richard, J. \& Obrien, S. J. (org.) Georgetown University. Round Table on Language and Linguistics. Washington, D.C.: Georgetown University, p. $35-56$.

. (1977). The Case for Case Reopened. In: Cole, P. \& Sadok, J. Syntax and Semantics: Grammatical Relations. New York: Academic Press. V. 8, p. 59-81.

FLORES, L. (1994). Teoria da correferencialidade com especial atenção ao português. Dissertação de Mestrado. Florianópolis: UFSC.

HALLIDAY M. (, 1968). Notes on transitivity and theme in english. In: Journal of Linguistics 3, p. 179215.

HOUAISS, A. (2001). Dicionário Houaiss da Língua Portuguesa. Rio de Janeiro: Objetiva.

LAKOFF, G. (1966). Stative Verbs and Adjectives in English. In: Dettingger, A. G. (ed), Mathematical Linguistics and Automatic Translation. Cambridge, Mass.: Havard University Press.

LANGACKER, R. (1975). Functional Stratigraphy. In: Grossman, R et. al. (eds), Funcionalism. Chicago: Goodspeed, p. 351-397.

LYONS, J. (1979). Introdução à Lingüística Teórica. Tradução de Rosa Virgínia Mattos e Silva e Hélio Pimentel. SP: Ed. Nacional, Ed da Universidade de São Paulo.

MARQUES, M. H. (1999). Iniciação à Semântica. 4 ed. RJ: Jorge Zahar.

McCAWLEY, J. D. (1976). Grammar and Mening. In: Papers on Syntatic and Semantic Topics. New York: Academic Press.

NICOLACÓPULOS, A. T. (1992). The Holistic Case: an Introduction to Case Grammar. Florianópolis: UFSC.

NICOLACÓPUlOS, A. T. et al. (1997). O Modelo Casual da UFSC. In: CÍRCULO DE ESTUDOS LINGÜÍSTICOS DO SUL, Florianópolis. Anais do $1^{\circ}$ CelSul. Florianópolis/SC, p. 203-209.

NICOLACÓPUlOS, A. \& ZUCCO, B. (1996). Teoria da Correferencialidade em Recortes Discursivos do Português (I e II). In: Revista UNIMAR, n. 18(1), p. 21-46. 
Cadernos de Estudos Lingüísticos 50(2) - Jul./Dez. 2008

OLIVEIRA, M. G. (1995). Predicações Polissêmicas e Metafóricas: uma Abordagem Semântico-pragmática. Tese de Doutorado. Florianópolis: UFSC.

OLIVEIRA, A. C. de. (1999). Cenas Benefactivas e Movimentos Semânticos no Contexto da Linguagem Jornalística. Tese de Doutorado. Florianópolis: UFSC.

PARSONS, T. (1994). Events in the Semantics of English. Massachusetts: MIT Press. 